\title{
CONVERSANDO COM RENATO TAPAJÓS
}

Cristine Fickelscherer Mattos *

https://orcid.org/ 0000-0003-2011-4614

Como citar este artigo: MATTOS, C. F. Conversando com Renato Tapajós. Todas as Letras - Revista de Língua e Literatura, São Paulo, v. 22, n. 2, p. 1-14, maio/ago. 2020. DOI 10.5935/1980-6914/eLETEN2013850

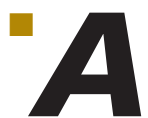

presentamos aos leitores da revista Todas as Letras a versão editada de uma longa conversa que o escritor, roteirista e cineasta Renato Tapajós travou em sua casa, em Campinas, com as Profas. Dras. Cristine Fickelscherer de Mattos e Helena Bonito Couto Pereira, editoras deste periódico, e a Profa. Dra. Fernanda Reis da Rocha, doutora egressa do Programa de Pós-Graduação em Letras da Universidade Presbiteriana Mackenzie, no qual desenvolveu pesquisa sobre a literatura brasileira da ditadura.

Renato Tapajós e sua esposa Marema (Maria Emir Valladão de Mattos), que trabalha na produção dos filmes do marido, receberam a equipe em sua residência, local em que puderam relatar experiências relevantes da história do nosso país, processos de criação, produção de cultura, entre outros temas. A participação e a representatividade de Tapajós nos cenários literário e cinematográfico do país, desde os anos 1960, fazem de sua voz um importante testemunho da nossa cultura.

Leia, a seguir, a edição da conversa, em forma de perguntas e respostas, versão adotada para condensar, de forma mais clara, quase duas horas de instigante diálogo ocorrido em 2 de julho de 2019. 
Fernanda Reis da Rocha (FRR) - No primeiro semestre deste ano, o seu último documentário Esquerda em transe, lançado em 2018, foi exibido em mostra e festival, além de ser bastante comentado na internet. Assim como em seus livros, o tema é político. Como foi a recepção ao documentário? Como é feita a divulgação de suas produções, como elas encontram o público, uma vez que estão fora do circuito comercial e dos interesses majoritários da grande mídia?

Renato Tapajós (RT) - Foi extremamente bem recebido. Normalmente, o público é o de universidades, grêmios estudantis, sindicatos e agremiações. É verdade que, de um modo geral, por causa de todos os filtros que esses ambientes têm, o público que vai ver os filmes já é um público predisposto a gostar do tema. E o que eu acho que acontece com os meus filmes é que o pessoal gosta não só pelo assunto, mas também pela maneira como eu trato; como o cinema que eu faço retrata esses assuntos.

Marema (MR) - Depois que o filme é lançado, ganha divulgação em circuitos paralelos (boca a boca e internet) e começam as solicitações de exibição. Foi o que aconteceu com $A$ batalha da Maria Antônia, que teve boa repercussão há cinco anos e agora com Esquerda em transe, exibido até no Acre.

Cristine Fickelscherer de Mattos (CFM) - Nesses locais, a exibição costuma ser gratuita e a divulgação em circuito paralelo pode gerar cópias. Como fica a questão dos direitos? Como se sustenta a sua produção?

R'T - Veiculação e cópia dos filmes para pessoas e grupos são gratuitas, contudo, quando envolve outras mídias que ganhariam público ou dinheiro com a exibição, já há mudanças. Nós tínhamos uma produtora, mas como não somos muito hábeis com negócios, ela faliu (risos). Nos últimos anos, os filmes que eu tenho feito são através da produtora do Júlio (Júlio Mattos), meu enteado, chamada Laboratório Cisco.

Helena Bonito Couto Pereira (HBCP) - Houve mudanças, ao longo dos anos, na sua forma de produzir livros ou filmes?

RT - Eu diria o seguinte: comecei pelo cinema e os meus primeiros filmes foram feitos dentro do movimento estudantil. Então, eles já tinham de imediato uma circulação grande e espontânea na época, que era de ditadura, entre tudo o que se produzia para criticar o governo ou alguns aspectos do sistema. Você perdia totalmente o controle a respeito do que acontecia com os filmes, mesmo com as dificuldades de uma época em que só havia película, sem as facilidades atuais. Meu cinema tinha um público bastante grande e ia muito rapidamente a todos os cantos do Brasil. Quanto à linguagem dos filmes, houve muita mudança. Se você vir os meus primeiros filmes e esses últimos, há muita diferença, que eu dataria. Eu fiz uma série de filmes antes de me "jogar" na militância, pois na clandestinidade, claro, não dava para fazer cinema. Fui preso, saí da cadeia e ainda fiz um ou dois filmes que seguiam o estilo inicial. O ponto de virada na minha produção foi Linha de montagem, filme para o qual nossa equipe conseguiu acesso direto ao sindicato, ao Lula. Para fazer esse filme convivi dois anos com eles. Com os livros, é outra história... 
MR - A produção de filme era autenticamente documental. Era ir filmando... não tinha roteiro, não tinha nada. Era só ir captando as imagens, por exemplo, ao acompanhar a greve dos metalúrgicos no ABC. Isso na década de 1980.

RT - Não tinha preparação prévia para o que estava sendo filmado, o que tinha era vivência, experiência e o registro disso. Eu trabalhava em cima desse material vivo. No meio daquele processo de filmagem, não tinha a menor ideia do que poderia acontecer. Era um sacrificio chegar a certo momento, parar e dizer: "Agora já tem material suficiente e já dá para parar e editar esse material", porque os processos seguiam adiante, com muita coisa acontecendo. Então, o que acabou ocorrendo é que começamos a editar, mas seguimos filmando mesmo no meio da edição, outras coisas que nem entraram no Linha de montagem, mas que serviram de material para outros filmes posteriores.

CFM - Linha de montagem retrata um momento politico agudo da nossa história. Como foi a recepção ao filme?

RT - O Linha de montagem, por causa do tema, do personagem, foi o meu primeiro filme que rompeu a barreira do âmbito receptivo a que estavam ligados meus filmes anteriores. Foi além desse âmbito. Teve um impacto político forte. Todos os sindicatos do Brasil projetaram esse filme. Passou no cinema, em cineclubes. Vários lugares, de capitais e do interior, me convidavam para ir debater o filme. Evidentemente, com essa repercussão, o Linha gerou muitas críticas, notícias, contra e a favor. No âmbito cinematográfico, também houve novidades. Eu comecei como cineasta ganhando prêmio fora do Brasil, mas na década de 1980, que concentra a maioria dos prêmios que recebi, houve reconhecimento nacional também.

HBCP - Você diria que essa produção ligada à vivência, ocorrida com seus filmes, estende-se também aos seus livros?

RT - Os livros e os filmes estão ambos voltados para o engajamento político e social. Eu participei da militância contra a ditadura e me mantive engajado depois de outras formas. Então, nesse sentido sim, falo de engajamento a partir de uma vivência. No caso de Em câmara lenta, a relação entre o que eu vivi e o que escrevi é mais direta porque escrevi enquanto estava preso. Eu precisava escrever...

FRR - Os personagens de Em câmara lenta são reais?

RT - Sim. Eu comecei escrevendo sem pensar exatamente que seria um romance. Quando a coisa foi tomando forma, deixou de ser só sobre o que tinha acontecido no movimento estudantil contra a ditadura ou com os integrantes desse movimento. Mas, sim, são reais. A Lola, por exemplo, era minha cunhada, irmã da minha primeira mulher, e foi assassinada de maneira brutal, como está no livro.

MR - O protagonismo de Lola está ligado a uma questão afetiva, pois Renato e ela eram muito amigos e essa amizade, durante a militância, foi se confundindo com uma paixão recolhida, misturada com admiração. Todos que a conheceram falam de seu magnetismo pessoal: era carismática, suave e forte, calma e determinada. 
CFM - Como foi para você escrever sobre pessoas tão próximas?

RT - Terrivel, mas era uma necessidade. Eu escrevi na prisão, quando fui preso da primeira vez. A segunda prisão foi, exatamente, por causa da publicação do livro. Então, tudo foi muito dificil, sofrido, pelas torturas, as mortes... e porque, claro, tudo tinha que ser feito secretamente. Logo que fui preso passei dez meses numa solitária. Só depois foi possivel escrever. Eu escrevia e passava tudo para um papel de seda com letra minúscula. Daí dobrava o papel até ficar do menor tamanho possível e embrulhava com o invólucro do cigarro e com durex. Minha mãe ou meu pai vinham me ver e levavam isso escondido na boca. Com a ajuda de uma lupa, minha mãe ia lendo para o meu pai datilografar.

HBCP - Por que Em câmara lenta não virou um belíssimo filme?

MR - Esse é um sonho eterno...

RT - Sim, algo que sempre ronda nossas cabeças... Eu pensei muitas vezes em fazer o Em câmara lenta como filme, porém nem cheguei à fase de propor. Fizemos o roteiro com o Hidalgo, sócio da produtora do Júlio, e percebemos que seria muito caro transpô-lo para um longa, por problemas com a produção, como caracterização de época, filmagens na Amazônia etc. Muita gente nos cobra a feitura desse filme até hoje. Mas lidamos sempre com o problema da falta de incentivo, de verba, de patrocínio no país. A maioria dos meus filmes, por serem documentários, tem um custo baixo de produção. É muito dificil fazer cinema. Mas, na temática de Em câmara lenta, realizamos Corte seco, que pode ser visto no YouTube. É uma narrativa de ficção, entre aspas, sobre a tortura no Brasil. Digo entre aspas porque tem um forte conteúdo autobiográfico, mas fala, antes de mais nada, do que aconteceu com muita gente naquela época. É um filme sobre uma realidade histórica e também atual, porque infelizmente, mesmo que com menos frequência, a tortura ainda é amplamente praticada.

FRR - Eu assisti a Corte seco e me impactou muito. É como uma provação para o espectador assistir a cenas tão terriveis. Um efeito de sentido que ocorre também, de maneira parecida, na leitura de Em câmara lenta. Foram efeitos de sentido pretendidos ao produzir o livro e o filme?

RT - O filme é impactante, transcende limites estéticos e de sentimento pessoal. A tortura que o cinema mostra, em geral, está revestida de certo idealismo, que justifica a sua existência na história. Eu quis mostrar a tortura em toda a sua crueza, em todo o seu sem-sentido, sem qualquer idealismo que a justifique. Por eu ter sentido na pele a tortura que retrato, isso exigiu certo tempo de afastamento: levei 30 anos para conseguir fazer esse filme, pois antes era dificil até mesmo pensar em tudo o que aconteceu. No caso do livro, já é totalmente diferente, porque eu comecei a escrever quando preso para expurgar o que vinha vivendo e depois, já fora da cadeia, trabalhei sobre o que tinha escrito pensando em leitores de esquerda que, bem ou mal, tinham conhecimento do que acontecia com os militantes.

CFM - E como foi a recepção do livro Em câmara lenta na época? 
RT - Muito boa. Surpreendente, na verdade. Então, veio a censura, o recolhimento do livro e a minha segunda prisão. Como o caso foi noticiado pela imprensa, o interesse pelo livro só aumentou. Passou a circular clandestinamente e foram feitas cópias xerox que foram lidas na Europa, na Argélia, em Angola e até mesmo em Moçambique (que estava em meio a uma guerra civil). Eu fui julgado na Auditoria de Guerra, e, no dia do julgamento, juntou um monte de gente, jornalistas e intelectuais de esquerda, claro, mas também leitores.

MR - Houve um movimento de intelectuais, escritores e jornalistas pela libertação do Renato. No Brasil e no exterior. Nos Estados Unidos, o dramaturgo Arthur Miller fez um abaixo-assinado muito divulgado. A prisão e a censura ao livro tinham sido feitas com base na Lei de Segurança Nacional, pela acusação de que o livro exaltava a guerrilha e estimulava a subversão da ordem. Então, o advogado do Renato pediu um parecer técnico sobre o livro ao professor de Teoria Literária e Literatura Comparada da USP, Antonio Candido. A defesa de Candido [anexada ao final] foi importante para que o processo contra o Renato fosse finalizado.

HBCP - Como você passou dessa experiência para a produção de literatura infantojuvenil?

RT - Pois é... eu sempre tive uma certa atração por esse tipo de literatura que é voltada aos jovens, porque eu lembrava do meu interesse por leitura quando eu tinha mais ou menos essa idade e da dificuldade que era encontrar obras adequadas. Na verdade, o que acabava acontecendo é que eu abria a biblioteca do meu pai e lia uma literatura que não tinha nada a ver com a minha idade. Nesse sentido, fui muito precoce na leitura de textos mais complicados. Lembro de ter lido Sartre a partir dos 10 anos mais ou menos. Eu acabei sendo muito influenciado por Sartre no período do final do curso secundário, na entrada na faculdade. Embora eu sempre tenha me dito comunista, eu tinha uma vertente existencialista muito marcada, porque eu li muito isso... Simone de Beauvoir... e outros. Li isso tudo muito precocemente. Bom, como eu tenho dois filhos do primeiro casamento, que hoje estão na faixa dos 40 anos, quando eles tinham 17, 16 anos, eu tinha muita vontade de conseguir fazer coisas que dialogassem com o universo deles. Como eu sempre conversei muito com eles, eu tinha uma ideia bastante boa do que que era aquela juventude. Então, comecei a escrever essa literatura infantojuvenil. E eu tinha, por causa do Em câmara lenta, contatos na Editora Ática, amigos, e eles abriram as portas para eu começar a publicar. E o resultado foi bom: os primeiros livros que eu escrevi tiveram uma boa acolhida. Foram distribuídos no Brasil inteiro e estiveram entre os mais vendidos, atrás apenas dos de Pedro Bandeira. E aí eu fiquei durante um período bastante grande focado nessa produção. E não é que o interesse tenha passado ou eu tenha desistido dela. O mercado editorial é que mudou: a Editora Ática foi vendida, o pessoal todo saiu e eu acabei me afastando.

FRR - A leitura de seus livros, nos meus anos escolares, foi determinante para a minha formação como leitora e para o meu gosto pela leitura e pela literatura. Para muitos de meus colegas também. Especialmente o livro A infância acabou. $O$ que em seus livros the parece responsável por esse resultado? 
RT - Creio que seja principalmente pelo fato de tratar da realidade dos jovens. Tanto no sentido do que estavam vivendo - situações, conflitos, preocupações, anseios -, que eu sabia por conta do que via através de meus filhos, quanto no sentido dos espaços que eu incluía, que eram cotidianos, reconheciveis. O personagem que anda pela Rua Augusta, que desce do ônibus no Ibirapuera... Enfim, eu procurava ser o mais realista possivel, no sentido de não trabalhar com situações e espaços idealizados.

MR - O resultado sempre foi muito claro. Dois exemplos: numa feira de livros em Passo Fundo, na qual o Renato tinha um pequeno stand de livros com grande fluxo de pessoas, surgiu uma professora apreensiva perguntando: "Quem é o Renato Tapajós aqui? A gente fez uma viagem de quatro horas do interior só porque os alunos querem muito conhecê-lo". Em outra ocasião, no municipio de Artur Nogueira, uma escola convidou-nos para uma Semana Renato Tapajós, com cartazes, fotos, adaptação teatral e produção de música a partir dos livros.

CFM - Vejo em todos os seus trabalhos um forte ingrediente social. Mesmo nos livros infantojuvenis, de forma muito bem contextualizada, está presente o olhar sobre como o sujeito se insere no contexto em que vive. Não de uma maneira panfletária, mas conscientizadora. Nunca pensou em se afastar desse viés por receio de não ser bem recebido ou por medo de ser mal-entendido?

RT - Eu sempre tentei manter distanciados os meus posicionamentos especificos da minha produção. Quer dizer, eu sempre achei que a literatura, e mesmo o cinema, perde quando se transforma numa coisa proselitista, com esse didatismo quase primário dos textos panfletários de conscientização. E embora eu tenha sido um militante totalmente envolvido com os processos da luta clandestina, até mesmo das ações armadas (que abandonei por total falta de afinidade, não sirvo para isso), eu sempre procurei manter uma independência naquilo que eu escrevo e nos filmes que eu faço. Sempre quis tentar encontrar a lógica interna das coisas, que não fica subordinada a essa dicotomia prévia. Isso sempre foi uma preocupação minha. Agora, medo a gente sempre tem. Atualmente, estamos com roteiro pronto e orçamento aprovado para a feitura de um filme que deve chamar-se Sombras sobre o continente, a respeito do momento politico presente da América Latina. O receio é inevitável.

HBCP - É possivel escapar à dicotomia ao falar sobre o que a história cristalizou com fortes polarizações?

RT - A gente tenta... (risos). Posso dar como exemplo o meu filme A batalha da Maria Antônia. Existe essa redução que, de maneira ideal, procura ver só dois lados extremos em tudo o que aconteceu. Mas a realidade é mais complicada. A partir de um olhar de dentro, dos que participaram, a gente pode pensar melhor esse episódio dentro do clima geral que havia na época.

FRR - Como foi a sua trajetória? Digo, como você saiu do Pará e se tornou militante, escritor e cineasta no Sudeste? 
RT - Bom... eu comecei a fazer cinema ainda em Belém, o filme Vila da Barca foi feito lá, onde eu tinha todo um envolvimento com os grupos de esquerda. Meu pai e uma das minhas tias tinham sido do Partido Comunista, quer dizer, eram do partido na época. Então, através de amigos e contatos deles, eu tinha um acesso bastante grande, não só à esquerda organizada, como aos movimentos. E o Vila da Barca foi uma coisa assim: o tema me interessou - a população que vive na água, que vive sobre a água e não encontra a possibilidade de construir suas casas em terra e, logo, tem de construir suas casas sobre palafitas. A filmagem foi extremamente experimental. Eu gostava de cinema, lia sobre, via filmes, mas não tinha ainda nenhum tipo de prática. Só depois, por causa da repercussão do filme, eu acabei sendo chamado para fazer publicidade e uma série de outros trabalhos que tinham a ver com imagem, edição de imagem etc. Eu estava experimentando. Tive apoio de um fotógrafo, mas metade do Vila da Barca fui eu mesmo que filmei porque eu queria ter a sensação, entender como era. É muito fácil você falar para alguém: "Faz isso, faz aquilo". Agora, saber o que ele está fazendo, saber como isso chega para ele, só se você põe a mão na massa. Foi um momento na minha vida muito significativo e específico, porque é exatamente a época do golpe de 1964. Antes de fazer Vila da Barca, em meados de 1964, depois do golpe, eu vi Deus e o diabo na terra do sol, e o filme - eu sempre falo isso - foi para mim uma iluminação. Já vi várias vezes, já estudei o filme, e nada se compara à sensação de deslumbramento com a qual eu saí depois de assistir àquela maneira de utilizar a música junto com as imagens e a forma de fazer as imagens. Quer dizer, a maneira de utilizar como uma linguagem aquilo que no cinema tradicional é defeito. Quando eu fui fazer o Vila da Barca, eu estava sob essa influência. Eu não diria uma influência do Glauber Rocha, porque os outros filmes dele já não tiveram o mesmo impacto sobre mim - tem coisas de que gosto e coisas de que não gosto -, mas o momento, reunindo o contexto, o filme assistido e a produção do Vila da Barca, ficou para mim como uma cortina que você abre e descobre, de repente, que tem um mundo lá fora, um sol. Eu fiz o possível para entrar nesse mundo.

\section{CFM - Foi para entrar nesse mundo que você veio para São Paulo?}

RT - Eu vim para São Paulo para fazer vestibular. Prestei para a Escola Politécnica da USP e entrei. Cursei um ano e meio, mais ou menos. Encontrei na Poli um grupo de cinema que se chamava Grupo Quatro, do qual saíram dois cineastas conhecidos: o João Batista de Andrade e o Francisco Ramalho. O Ramalho, desde cedo, optou pela ficção, mas o Batista se tornou documentarista e é um dos documentaristas significativos desse período todo, não só pelos filmes independentes que ele fez, mas por ter trabalhado um tempo com o Globo Repórter e em outras instituições. Então, essa passagem pela Poli, o contato com gente que já fazia cinema lá, transformou aquele meu deslumbramento inicial em uma coisa mais prática: não é só uma festa, trata-se de uma profissão que sacrifica as pessoas, que tem dificuldades muito grandes e que precisa de estudo. Você não pode fazer cinema a olho, você tem que estudar o que já foi feito com a linguagem cinematográfica. Eu me dediquei em paralelo a esse estudo. Nesse meio-tempo, eu desisti de ser engenheiro e fiz vestibular para Ciências Sociais, também na USP. Lá eu encontrei o meu mundo, e como eu me liguei logo ao Grêmio, começaram a surgir conversas sobre a possibilidade de levantar algum dinheiro para fazer filmes. $\mathrm{O}$ 
primeiro deles foi o Universidade em crise, que é uma discussão sobre a universidade naquele momento. O Grêmio, além de me dar a possibilidade de fazer cinema, fez surgir o aspecto político. Quer dizer, eu não conseguia fazer cinema sem me envolver politicamente com o movimento estudantil. E eu muito rapidamente fiz amizade e me liguei com as lideranças estudantis. Fazer cinema, fazer politica e estudar consumia todo o meu tempo. Mas era muito bom.

FRR - Você chegou a participar da guerrilha no Pará, que está narrada no livro Em câmara lenta?

RT - Não. Naquele momento eu estava já em São Paulo, totalmente envolvido com o movimento clandestino urbano. Eu convivi com pessoas que participaram, mas não participei.

HBCP - O livro desnuda o movimento da guerrilha e nos oferece uma visão crítica sobre ele. O militante Renato Tapajós já tinha essa visão crítica ou isso veio só depois, na época de escritura do livro?

RT - Como eu falei, meu pai e minha tia eram do Partidão. Mas naquele momento de radicalidade da repressão que a gente estava vivendo ali, o Partidão não tinha nada a ver. Aí eu me liguei ao PCdoB, que era a dissidência chinesa do Partidão, era maoísta. O Partidão tinha se dividido em PCdoB e PCB. Nem bem eu estava há três, quatro meses dentro do $\mathrm{PCdoB}$, eu já estava numa dissidência dentro dele, porque eu pensava assim: o PCdoB fala tanto em revolução e não está fazendo nada. Eu me irritava quando os dirigentes diziam que as ações revolucionárias eram secretas. E eu pensava: secretas para os militantes? Como assim, secretas? Então, eu e outros do PCdoB formamos a Ala Vermelha, com objetivos mais imediatos, pela necessidade de ações armadas e uma série de coisas desse tipo, que eram todas práticas, e que acabaram nos aproximando da dissidência do PCB, a Aliança Libertadora Nacional (ALN).

MR - Hoje em dia, com uma oposição mais intelectual, pode ser difícil imaginar o lado prático da militância. Havia treinamentos para a guerrilha, destinados a formar integrantes como soldados, preparados para sobrevivência na selva e tudo. Era a contrapartida da violência extrema da ditadura.

R'T - A opção de ser só intelectual nunca me pareceu muito agradável. Cheguei a participar de treinamento também, mas não me adaptei. Pegar em armas, isso não era para mim. Meu desejo era ser guerrilheiro urbano, porque guerrilheiro urbano você planeja as coisas sentado, dentro de casa, depois vai e faz a ação - e você vai de carro! (risos).

HBCP - Apesar de toda a organização da militância, o livro Em câmara lenta desnuda as contradições internas, o despreparo dos guerrilheiros e seu trágico destino. É o que me parece mais realista e tocante na obra. Além da visão crítica que sempre o acompanhou, como foi a sua experiência de "cair"?

RT - Bom, eles acabavam capturando pessoas meio a olho no universo da esquerda, dentro e fora do meio estudantil, e as pessoas eram levadas e entravam 
no maior "cacete". Então, uma dessas que foi presa, "abriu" a existência do nosso "aparelho", onde a gente ficava. Aí, quando eles estouraram o "aparelho", eu não estava, mas as pessoas que foram pegas levaram um "tremendo cacete" e acabaram dando as indicações de onde eu poderia estar. Eu fui preso na rua e essa cena da prisão está mostrada no filme Corte seco. Essa foi a primeira prisão. A segunda, por causa do livro, como eu estava trabalhando na Editora Abril na época, eles estavam me esperando na portaria da editora e me levaram de lá; e, aliás, a Abril era conivente. Mas nunca me deixei abater psicologicamente, porque fazia parte, estávamos sempre prevendo que acontecesse. Também não havia incentivo a discurso de ódio ou revanche. A luta era exclusivamente política. A ALN fez algumas execuções, mas a nossa organização, não.

CFM - Como depoimento final, como você gostaria de concluir?

RT - Não sei exatamente o que dizer... Bom, eu vou fazer um comentário sobre esse momento que estamos vivendo. Olha, eu atravessei tudo isso, fui preso, fiquei cinco anos preso, fui torturado, estive em solitária, fiquei com sequelas da tortura, depois tive um monte de problemas com o livro, ou seja, enfrentamos os governos da ditadura, os generais todos que vieram depois, e eu nunca tinha ficado deprimido. Nunca. A minha história de vida é de nunca ter tido uma crise de depressão. Aí, o que estamos vivendo no país agora conseguiu. Todo o desmonte que vem sendo feito. A conspiração, que agora se revela, feita para prender o Lula e fazer o impeachment da Dilma. Eu realmente me senti muito mal com isso. Está certo que, depois das mudanças dos governos anteriores, era possivel essa reação da direita, mas não da maneira como vem ocorrendo. 


\section{Anexo}

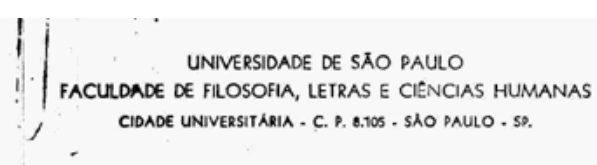

P A R E C E R .

Tendo sido indicado como Perito no Processo movido contra o escritor Renato Tapajós, por causa da publicação de seu romance "Em câmara lenta", penso que os pontos importantes, no caso, são os seguintes:

1. este livro é subversivo?

2.a sua leitura induz a uma atitude subversiva, ou à prática de atos subversivos?

Antecipo que a resposta é - "Não", - pelos motivos abaixo discriminados.

1. "Em câmara lenta" não é um livro subversivo, devido a uma série de razões. Em primeiro lugar, porque é um romance e, portanto, escrito num tipo de discurso narcado pela predominância da "função poética" (Jakobson), isto é, a que se caracteriza pelo fato da palavra ter a si mesma como finalidade ṕrincipal; pelo fato da palavra ser trabalhada em função das suas pbopriedades específicas.

No discurso literário existem, é claro, outras funções da linguagem, como a "referencial", cuja finalidade é a represen-. tação objetiva do mundo interior e exterior. Mas os diversos tipos de discurso se caracterizam pela predominância, não a exlusividade de funções. Na linguagem quotidiana, no discurso administrativo ou científico, por exemplo, predomina a função referencial, que visa a informar, a exprimir diretamente o que percebemos ou infermmos da realidade. Na linguagem literária, predomina a função poétıca, que visa a realçar as qualidades estéticas da palavra. Não prode, portanto, tomar como informativo, como documento, um discurso de tipo literário, que visa a criar un universo específico, diferente da realidade, embora a tenha como matéria prima e procure

Mod. 02.03.037-350x50 - 6-72

Seçio Grálica F.F.L.C.H., U.S.P. imprimiu

- ilit il 
UNIVERSIDADE DE SÃO PAULO

FACULDADE dE FILOSOFIA, LETRAS E CIENCIAS hUMANAS

CIDADE UNIVERSITARIA - C. P. 8.105 - SAOO PAULO - SP.

tomar o seu lugar. Um erro vulgar consiste em pensar que a força da literatura vem da realidade que descreve; quando, de fato, esta força provém do teor estético da lineragem usada. O sentimento real, por exemplo, não basta para fazer literatura, porque, ao contrário do que tendemos a pensar, o que nos toca não é a autenticidade objetiva disso ou daquilo, mas a eficĩência estética do discurso, que faz parecer autêntico isso ou aquilo (mesmo que não $\circ$ seja).

A estas considerações é preciso juntar outra, de grande importância: a que se refere ao caráter de ambiguidade do discurso literário. Neste, as coisas, os sentimentos, as idéias, nunca têm um único significado, mas vários; e isto faz a sua força. Daí a necessidade de "interpretação", que é o modo de ler literatura, sendo uma tentativa de estabelecer quais são os sentidos possíveis, de cujo concurso se forma o, ou se formam os, significados dominantes.

Pelo exposto, vemos que é arriscado tomar como documento um romance, que foi construído deliberadamente como obra literária, portanto artificial, com predomínio da funçäo poética e alta taxa de ambiguidade.

"Madame Bovary", de Flaubert, é pró ou contra o adultério? "Abusca do tempo perdido", de Proust, é uma apologia ou uma condenação do homossexualismo? "Sob o olhar do Ucidente", de Conrad, exalta ou denigre os revolucionários? Todas estas questões são secundárias e, na verdade, inócuas. Quando alcança o devido nível literário, o romance ultrapassa tais dilemas e se apresenta como um feixe de possibilidades de significar. Como a vida, elevnos deixar perplexos, nos levai ao tacteio, ao erro de visão; mas, como ela, enriquece, enquanto totalidade de experiencia.

"Em câmara lenta" não é um retrato documentário, continuo e fiel da realidade. E escrito conforme uma técnica requintada de fragmentação do real, mistura de planos temporais, visão rota- 
UNIVERSIDADE DE SÃO PAULO

faculdade de fllosofia, letras e ciencias humanas

CIOADE UNIVERSITARIA - C. P. B.1OS - SAO PAULO - SP.

tiva, - tudo ordenado em torno da ação que se completa aos poucos e dá nome ao livro. E não apresenta um sienificado, mas uma série deles tantos, quantas sũo as faces da realidade e os correspondentes ângulos de visão.

2. Isso leva à seerunda pergunta: a sua leitura induz a uma atitude subversiva, ou à prática de atos subversivos?

No meu entender, não. Um leitor de "Em câmara lenta" pode se interessar pelos dramas pessoais, pela sucessão de atos, pelo suspense das cenas, pelas imagens poéticas, etc. E, sobretudo, pelo mistério lertanente desvendado da cena central recorrente; do ato que vai se perfazendo aos pedaços, até compor uma ação total. Trata-se, pois, de interesse cuja natureza é sobretudo estética. É claro que o leitor poderá ter uma visão panorâmica de atos revolucionários, apresentados nas suas diversas dimensões e podendo, sem dúvida, constituir uma visão polf́tica, um modo: de conceber a participação nos problemas do nosso tempo. Was não vejo, em momento algum, convite à prática, induzimento, ou sequer sugestão por mejo do embelezamento ou realce do que é descrito, - como ocorre nos romances doutrinários e, em Eeral, alegóricos, que estiveram em moda sobretudo até o século XVIII. "Em câmara lenta" nada tem a ver com este Eênero, hoje relegado ao 'segundo time da f1cção. E note-se que no Iivro não há sequer (como é frequente nos romances de cunho naturalista) descrição pormenorizada de atos revolucionários. Como vimos, a narrativa, muito moderna, é descontínua, fragnentada, procede por flashes que adquirem certo tom de irrealidade e entra por vezes na dimensão atemporal, que nos arranca do quotidiano presente para entrar no universo da fábula realista.

3. Alguém poderá fazer uma reflexão como esta: admitindo embora isso tudo, a leitura de um livro não pode, entre as suas diversas interpretações possf́veis, levar entre outras a uma con-

Mad. $02.03 .037-350 \times 50-6-72$

Secefio Grifica F.F.L.C.H.,U.S.P. inprimiu 
UNIVERSIDADE DE SÃO PAULO

FaCULADE DE FILOSOFIA, LETRAS E CIENCIAS hUMANAS

CIDADE UNIVERSITARIA - C. D. Q.105 - SAOO PAULO - SP.

clusão de ordem prática? Portanto,uma pessoa que lë "Em câmara lenta", mesmo plenamente capacitada da sua natureza de produto ficcional, não pode extrair uma determinada conclusão de vida? Apesar de toda a neutralidade de Flaubert, o leitor de "Madame Bovary" não pode, por sua conta, concluir que o adultério é bom?

- Sim, isso é possível. É possível que o leitor de "Em câmara lenta", tudo sentido, tudo vivido, tudo pesado, tire da sua interpretação una conclusäo prática do que leu. E qual seria ela? Poderia (voltando ao nosso tema) ser um convite, ou induzimento à subversão?

Admitindo para areumentar e por dever de probidade este plano meramente pragático e portanto secundário de leitura, que não me interessa enquanto crítico literário, eu concluiria, mais uria vez, pela resposta negativa que antecipei no começo. Com efeito, note-se que a partir da página 186 o livro vai tecendo uma série de dúvidas, de proposições alternativas, de críticas ao tipo de atividade descrita. Ressalvando a ambiguidade dos textos literários, o que pessoalmente infiro, se me situo neste plano, é uma sugestão, indireta, não formulada, mas poderosa, contra a subversão. Sugestão contra a eventual inutilidade de tudo que se descreveu. Parece haver no fim do livro, com efeito, uma atmosfera que faz sentir como são inúteis os tipos'de ação que nutrem a narrativa; como é negativo o caráter isolado e quase antisocial do guerrilheiro; como é vazia a acção humana que não se enquadra nos desífnios, na vontade dos outros homens, de uma coletividade.

4. Resumindo para concluir: em qualquer nível que me coloque, sou levado a negar que "Em câmara lenta" constitua um inzentivo ou sequer um mero exenplo para a atividade subversiva. E se fosse necessário extrair dele uma licão, como dos velhos romances alegóricos, eu concluiria que é, antes, o contrário. 
UNIVERSIDADE DE SÃO PAULO

faculdade de fllosofIa, letras e ciencias humanas

CIDAde UnIVERSITARIA - C. R. 2.10s - SAOO PAULO - Sp. .

Esta é a opinião que emito, cônscio da minha responsabilidade e com base em análise atenta, como professor, crítico e estudioso de literatura.

São Paulo, 12 de feverelro de 1978

\author{
A.erlintin. \\ Antonio Candido de Mello e Souza \\ Professor Titular Aposentado da \\ Universidade de São Paulo. Coor- \\ denador do Instituto de Estudos \\ da Linguagem da Universidade Es- \\ tadual de Campinas.
}

